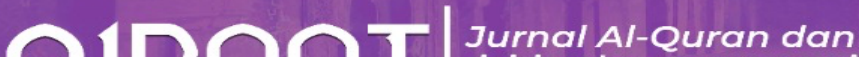 \\ isi-isu kontemporari \\ e-ISSN : 2636-9591
}

Jurnal Qiraat

Fakulti Pengajian Peradaban Islam,

Kolej Universiti Islam Antarabangsa Selangor (KUIS)

Bandar Seri Putra, 43000 Kajang Selangor

20XX, VOL X, Bil X, Halaman XX

\section{Title: Relevansi Qirāāt dan Implikasinya Terhadap Hukum Fiqh : Satu Pengenalan}

\section{[The Relevance of Qirāāt and Its Implications for Hukm Fiqh: An Introduction]}

\section{Author: Muhammad Zaid Shamshul Kamar ${ }^{1 *}$, Muhammad Fairuz A.Adi, ${ }^{1}$ Shaharuddin Saad $^{1}$ Hanis Muhammad Radhi ${ }^{2} \&$ Muhammad Zainol Arifin Md Tahir ${ }^{3}$}

\footnotetext{
${ }^{1}$ Jabatan Tahfiz al-Quran \& al-Qiraat, Fakulti Pengajian Peradaban Islam, Kolej Universiti Islam Antarabangsa Selangor, 43000, Malaysia, muhammadzaid@kuis.edu.my, +6011-2362 4943.

2 Pelajar, Jabatan Tahfiz al-Quran \& al-Qiraat Kolej Universiti Islam Antarabangsa Selangor, 43000, Malaysia, hanisradhi20@gmail.com, +6019-2893656.

${ }^{5}$ Pegawai, Masjid Sri Sendayan,71950, Malaysia, Zainoltahir91@gmail.com, +6013-331 2914.
}

* Corresponding Author: Muhammad Zaid Shamshul Kamar. Jabatan Tahfiz al-Quran \& al-Qiraat, Fakulti Pengajian Peradaban Islam, Kolej Universiti Islam Antarabangsa Selangor, 43000, Malaysia, muhammadzaid@kuis.edu.my, +6011-2362 4943, ORCID iD.

\section{ABSTRACT}

The knowledge of qirāāt is a very important in Islamic studies. This discipline of knowledge is closely related to a variety of other disciplines of knowledge including fiqh. This paper aims to state the role of the science of qirāāt in influencing the production of hukm fiqh for the fuqaha. Also discussed are the definition of qirāāt and fiqh, the role of khilaf qirāāt in shaping the hukm fiqh, the role of qirāāt in improving the understanding of the verses of fiqh as well as qirāāt and its effect on fiqh. This writing is qualitative and historical in nature. The result of the study is to explain the implications of qirāat on the provisions of the jurists in the production of hukm fiqh. There are two divisions of the effect of khilaf qirāāt on fiqh. The first is the part that plays more of a role in the description, explanation and expansion of meaning in fiqh. The second is the part that leaves a more specific impact on the differences of fiqh law among the fuqaha following from the qirāāt khilaf that exist. Also included are two examples and descriptions for each division. Therefore, the study of the science of qirāāt and its interaction with the hukm of fiqh should be developed in order to ensure the sustainability of knowledge, especially related to qirāât, is always preserved.

Keywords

Qirāāt, hukm fiqh, implications, interaction 


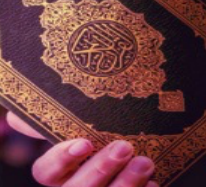

\begin{abstract}
ABSTRAK
Ilmu qirāāt merupakan ilmu yang sangat penting dalam pengajian Islam. Disiplin ilmu ini mempunyai kaitan yang rapat dengan dengan kepelbagaian disiplin ilmu yang lain termasuk fiqh. Penulisan ini bertujuan untuk menyatakan peranan ilmu qirāāt dalam mempengaruhi pengeluaran hukum fiqh bagi para fuqaha. Turut dibincangkan adalah definisi qirāāt dan fiqh, peranan khilaf qirāāt dalam mencorakkan hukum fiqh, peranan qirāāt meningkatkan pemahaman ayat-ayat fiqh serta qirāāt dan kesannya terhadap fiqh. Penulisan ini bersifat kualitatif dan persejarahan. Hasil kajian adalah untuk menjelaskan berkenaan implikasi qirāāt terhadap kententuan para fuqaha dalam penghasilan hukum fiqh. Terdapat dua pembahagian kesan khilaf qirāât terhadap fiqh. Pertama adalah bahagian yang berperanan lebih kepada huraian, penjelasan serta peluasan makna pada fiqh. Kedua adalah bahagian yang meninggalkan kesan yang lebih spesifik pada perbezaan hukum fiqh dalam kalangan fuqaha berikutan dari khilaf qirāāt yang wujud. Turut disertakan dua contoh dan huraian bagi setiap pembahagian. Oleh itu, kajian terhadap ilmu qirāāt dan interaksinya pada hukum fiqh seharusnya dikembangkan demi memastikan kelestarian ilmu khususnya berkaitan qirāāt sentiasa terpelihara.
\end{abstract}

Keywords

Qirāāt, hukum fiqh, implikasi, interaksi

\title{
1.0 PENGENALAN
}

Perbahasan tentang ilmu qirāāt sering diberi perhatian dan mendapat tempat di kalangan para ulama, sarjana, pengkaji dan para penuntut ilmu. Para ulama yang berinteraksi terus dengan disiplin ilmu qirāāt ini dilihat tidak pernah berhenti membincangkan akan kepentingan, peranan, dan kesan kepelbagaian khilaf qirāāt terhadap ayat-ayat al-Quran itu sendiri. Para fuqaha juga tidak ketinggalan membicarakan peranan ilmu qirāāt menurut kepakaran masing-masing khususnya dalam mencari jalan keluar bagi mendapatkan hukum yang tepat.

Sehubungan itu, penulisan ini akan membincangkan berkenaan pengaruh ilmu qirāāt sebagai mekanisme utama dalam menentukan hukum fiqh dalam kalangan ulama mazhab. Perbincangan ilmu ini mengambil pendekatan membahaskan beberapa aspek yang dilihat menjadi sandaran utama yang mempengaruhi kesan terhadap perubahan hukum fiqh.

\subsection{DEFINISI QIRĀĀT MENURUT SARJANA ISLAM}

Pentakrifan ilmu qirāāt telah dibahaskan oleh para cendekiawan Islam melalui kepelbagaian gaya takrifan mengikut kepada olahan masing-masing. Menurut al-Zarkashi (2001), qirāāt adalah perkara khilaf yang wujud di dalam pembacaan al-Quran mengenai huruf-hurufnya dari aspek tebal, nipis dan seumpamanya. Al-Suyuti (t.th) pula menyatakan bahawa qirāāt merupakan khilaf yang berlaku dalam kalangan imam yang tujuh mahupun sepuluh dan persepakatan pada turuq bacaan dan periwayatan.

Mohamad Sabri (2016) menyatakan bahawa Muhammad Salim Bazamul di dalam tesis peringkat doktor falsafahnya telah menyenaraikan sepuluh takrif ilmu qirāāt yang dijelaskan oleh para sarjana Islam. Antara 


\section{Q1PPPT|Jurnal Al-ouran dan

perbahasan yang terkait adalah perkataan qirāāt dari sudut etimologi dan terminologi. Dari aspek etimologi

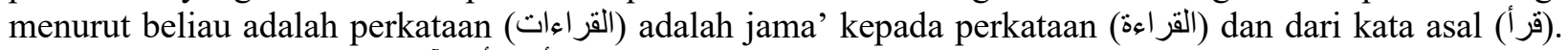
Dikatakan (قر أ, يقر أ, قر آنا, بمعنى تلا فهو قارى membawa maksud : Dia telah membaca, sedang membaca, bacaan, yang dibaca, dengan makna membaca dan pembaca (Majma' al-Lughah al-'Arabiyyah 1985).

Melihat dari aspek istilah, menurut Imam Ibn al-Jazari (t.th), qirāāt merupakan sebuah ilmu tatacara mempraktikan kalimah-kalimah al-Quran dan perbezaan yang disandarkan kepada periwayatnya. Sheikh 'Abd al-Fattah al-Qadi (2004) mengatakan qirāāt adalah satu ilmu yang diketahui dengannya tatacara pembacaan kalimah-kalimah al-Quran dan kaedah mempraktikkannya sama ada yang disepakati mahupun diperselisihkan wajah bacaan tersebut.

Penjelasan yang dikemukakan tersebut adalah dari jalan kajian, pengajian serta keilmuan yang mendalam para cendekiawan Islam tersebut terhadap ilmu qirāāt. Setiap konsep yang diutarakan adalah untuk memudahkan para pembaca untuk memahami makna ilmu qirāāt dari perspektif mereka.

\subsection{DEFINISI FIQH MENURUT SARJANA ISLAM}

Fiqh dari aspek bahasa berasal dari kata nama terbitan yang berasal dari kata dasar fi'il mādī (kata kerja lepas) iaitu ( فقا, يفقة, فقها ) yang membawa maksud mengerti, mengetahui, memahami dan menuntut ilmu (Al-Mu'jam al-Arabi al-Asasi 2003).

Dari sudut isitlah, fiqh ialah mengetahui hukum-hukum syara yang tertakluk kepada perbuatan dan perkataan orang yang mukallaf yang terdapat padanya dalil-dalil tafsil (dalil dari nas al-Quran, hadis, ijma dan qiyas) (Said Ibrahim 2000). Al-Zuhayli (1996) menyatakan bahawa fiqh adalah pengetahuan tentang hukum amali yang dirumuskan daripada dalil terperinci dalam al-Quran, sunnah dan sebagainya.

Selain itu, fiqh juga membawa maksud kefahaman berkenaan sesuatu perkara. Sebahagian ulama menyatakan bahawa kefahaman tersebut merujuk kepada suatu perkara yang sukar. Pada awal kedatangan Islam, fiqh sinonim dengan maksud agama atau hukum-hakam yang terkandung di dalam al-Quran dan hadis. Setelah beberapa ketika, konsep itu berbeza mengikut evolusi tempat dan zaman yang akhirnya membawa maksud fiqh adalah kefahaman tentang agama Islam (Hapiz, 2019).

Ijtihad hukum dalam ruang lingkup fiqh yang diutarakan oleh para mujtahidin adalah berdasarkan kepada kepakaran, kefahaman, penelititan serta analisis mereka terhadap dalil-dalil syariah di samping mengambil kira faktor utama yang lain seperti penggunaan bahasa, budaya masyarakat setempat, perubahan satu-satu tempat dan zaman.

\subsection{PERANAN KHILAF QIRĀĀT DALAM MENCORAKKAN HUKUM FIQH}

Setiap disiplin ilmu mempunyai peranan yang tersendiri dalam mempengaruhi pengajian Islam termasuk ilmu qirāāt. Dalam urusan istinbat hukum fiqh atau pengeluaran hukum fiqh, disiplin ilmu qirāāt mampu membantu memberi ketetapan terhadap hukum fiqh secara lebih terperinci. Para fuqaha tidak hanya bersandarkan kepada qirāāt yang mereka amalkan sahaja untuk mengeluarkan hukum fiqh. Bahkan, mereka turut melihat kepada perbahasan qirāāt yang lain. 


\section{Q1PคPT|Jurnal Al-Quran dan

Khilaf qirāāt pada lafaz mahupun kalimah dilihat mempengaruhi makna dan kadangkala memperkuatkan lafaz antara satu sama lain (A'tarahim 2016). Selain itu, kekuatan pengaruh khilaf qirāāt dilihat semakin jelas sekiranya dikaji pada ayat-ayat yang mempunyai khilaf tersebut dari aspek Bahasa, pentafsiran para ulama tafsir serta pandangan yang berbeza dari para fuqha. Hubungan antara pelbagai disiplin ilmu tersebut seperti qirāāt, Bahasa dan fiqh menjelaskan bahawa para ulama amat menitikberatkan perbincangan khilaf qirāāt dalam memahami dan mengeluarkan hukum dari nas-nas al-Quran.

Kesemua bentuk khilaf qirāāt yang mutawattir bahkan syadhdhah adalah diambil kira oleh para ulama. Hal ini kerana khilaf qirāāt tersebut tidak terkeluar dari landasan atau disiplin ilmu Bahasa Arab yang betul. Melalui sudut pentafsiran, ia membantu untuk memahami dan mendalami ilmu al-Quran dengan lebih baik serta membantu menghasilkan istinbat hukum yang tepat (A'tarahim 2016; Hapiz 2019). Secara tidak langsung, hal ini mampu mempengaruhi dalam aspek penentuan hukum fiqh dalam kalangan fuqaha.

Selain itu, terdapat juga pandangan tentang khilaf qirāāt yang khusus yang berkait dengan ayat-ayat hukum serta mempengaruhi istinbat hukum iaitu ('Adzim 2016; Wan Hakimin et.al 2017);

1. Mengukuhkan ketentuan hukum yang telah disepakati dan ijma oleh para ulama.

2. Men-tarjih hukum yang khilaf oleh para ulama.

3. Mengabungkan dua ketentuan hukum yang berbeza.

4. Menunjukkan terdapat hukum berbeza walaupun di dalam ayat yang sama.

5. Menjadi hujah ulama untuk memperkuat pendapat mereka.

6. Memberi penjelasan berkenaan suatu hukum dalam ayat yang berbeza dengan makna menurut dzahir.

7. Berperanan sebagai penterjemah terhadap suatu lafaz dalam al-Quran yang mungkin sukar untuk difahami maknanya.

\subsection{QIRĀĀT MENINGKATKAN PEMAHAMAN AYAT-AYAT FIQH}

Khilaf qirāāt secara tidak langsung berinteraksi dengan ilmu fiqh itu sendiri. Ini dibuktikan dengan perkembangan intelektual ilmu fiqh para kalangan fuqaha. Ketika para fuqaha berada dalam proses untuk berijtihad, mereka akan mengistinbat suatu hukum fiqh dalam satu-satu permasalahan dari nas al-Quran secara asasnya dan turut menilai kepada lafaz tersebut melalui pelbagai sudut sebelum mengeluarkan satusatu hukum untuk mazhab masing-masing. Penilaian tersebut membawa kepada kajian terhadap kepelbagaian disiplin ilmu seperti bahasa Arab, nas-nas sokongan untuk menguatkan hujah dan penafsiran yang pelbagai (A'tarahim 2016).

Selain itu, khilaf qirāāt juga dilihat menjadikan qirāāt sebagai hujah yang sangat kuat dan jelas untuk dipegang dan dipraktikan. Perkara ini dibuktikan pada fungsi lafaz qirāāt yang menghimpunkan antara dua hukum yang berbeza seperti pada kalimah (واتخذو) yang berkait dengan maqam Nabi Ibrahim AS. Khilaf qirāāt berkemungkinan juga menjadi syarat terhadap suatu hukum yang disepakati seperti pada kalimah (يطهرن) yang berkaitan dengan hukum haid. Khilaf qirāāt juga berkemungkinan menjadi batu asas kepada kepelbagaian pendapat serta ijtihad para ulama dan mujtahid seperti pada kalimah (لمستر).

Kebanyakkan ayat-ayat di dalam al-Quran yang mempunyai khilaf qirāāt menampakkan ilmu qirāāt sebagai sebuah ilmu yang sangat penting terutama dalam menentukan sesuatu hukum. Bahkan, khilaf tersebut tidak menidakkan makna kepada khilaf qirāāt yang lain tetapi menjadi dalil yang sangat kuat dalam menerangkan 


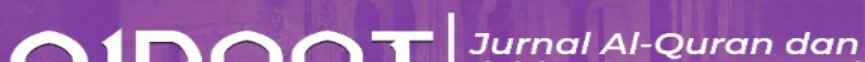 isi-isu kontemporari

serta membenarkan hukum yang lain seterusnya memberi kemudahan kepada umat Islam terutama untuk beribadah kepada Allah SWT.

\subsection{QIRĀĀT DAN KESANNYA TERHADAP FIQH}

Ibn al-Jazari (t.th) menyatakan terdapat kolerasi hubungan antara qirāāt dengan sebahagian hukum yang terbit dari khilaf qirāāt tersebut. Pengambilan qirāāt yang berbeza menatijahkan hukum yang berbeza dengan mazhab fuqaha yang lain. A'tarahim (2016) mengklasifikasikan kesan khilaf qirāāt terhadap fiqh kepada dua bahagian. Pertama adalah bahagian yang berperanan lebih kepada huraian, penjelasan serta peluasan makna pada fiqh. Kedua adalah bahagian yang meninggalkan kesan yang lebih spesifik pada perbezaan hukum fiqh dalam kalangan fuqaha berikutan dari khilaf qirāāt yang wujud. Berikut adalah contoh untuk dua pembahagian kesan khilaf qirāāt terhadap fiqh;

5.1 Contoh isu permasalahan serta qirāāt yang berperanan lebih kepada huraian, penjelasan serta peluasan makna pada fiqh;

\subsubsection{Muamalah Riba}

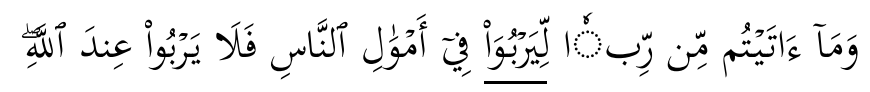

Maksudnya;

"Dan sesuatu riba (tambahan) yang kamu berikan agar dia bertambah pada harta manusia maka riba itu tidak menambah pada sisi Allah SWT".

(Surah Ruum 30:39)

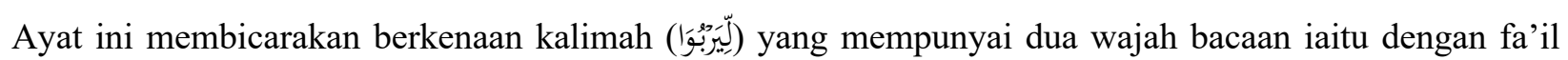
yang berbeza (A’tarahim 2016);

a. Imam Ibn Kathir, Imam Abu 'Amru, Imam Ibn 'Amir, Imam 'Asim, Imam Kisaei dan Imam Khalaf

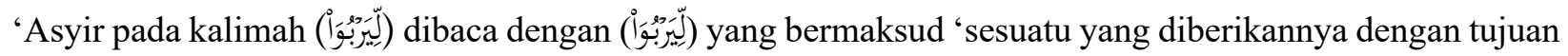
penambahan (riba)'. Ini menunjukkan bahawa pengharaman riba iaitu adalah dalam konteks menyeluruh walaupun tidak diketahui tujuan pemakan riba itu dengan jelas.

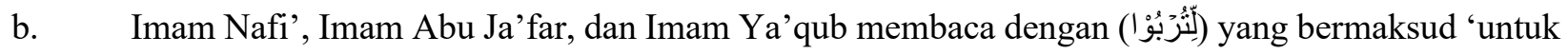
kamu menambah wang bagi sesiapa yang memberi riba'. Ini menunjukkan bahawa pengharaman riba bagi yang bergelumang dalam aktiviti tersebut. 


\section{Q1PPPT|Jurnal Al-ouran dan

\subsubsection{Pelaksanaan Sumpah Lian}

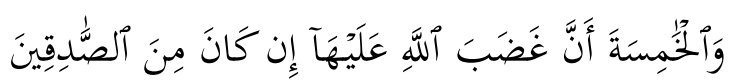

Maksudnya;

"Dan Sumpah yang kelima: bahawa laknat Allah ke atasnya jika suaminya itu termasuk kalangan orang-orang yang benar."

(Surah Nūr 24:9)

a. Imam 'Asim, Ibn Kathir, Abu Amru, Ibn Amir al-Kisaei, Abu Jaafar, dan Hamzah pada kalimah (أَ) dibaca dengan fathah dan tasydid manakala kalimah (أَنَّ) diba dengan fathah pada huruf ad-dha (غَضَبَ). Tasydid tersebut menggambarkan betapa benarnya (ta'kid) berlaku kemungkaran Allah ke atasnya di akhirat kelak (azab seksa yang pedih) jika pembuat itu berdusta.

b. Imam Nafi' membaca secara takhfif pada kalimah (أَن) manakala pada kalimah (غَضَ) dibaca secara berbaris kasrah pada ad-dha (غَضِ). Manakala Imam Yaakub membaca secara takhfif pada kalimah (أَن) manakala pada kalimah (غَضَنَبَ) dibaca secara berbaris fathah pada ad-dha dan dhommah pada al-ba (غَضَبُُُ). Takhfif tersebut menggambarkan tentang penangguhan hukuman ke atas pelaku pada ketetapan yang lain.

5.2 Contoh qirāāt yang meninggalkan kesan yang lebih spesifik pada perbezaan hukum fiqh dalam kalangan fuqaha ;

\subsubsection{Permasalahan Haid}

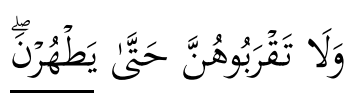

Maksudnya:

"Dan janganlah kamu mendekati mereka, sebelum mereka suci. apabila mereka telah suci".

(Surah al-Baqarah 2:222)

Ayat ini membicarakan berkenaan kalimah (يَطُُُرْنَ) yang mempunyai dua wajah bacaan iaitu dengan takhfif (lembut) dan tasydid (bersabdu) (Rahmani 2010; Wan Hakimin et.al 2017). 


\section{Q1PAPT|Jurnal Al-Quran dan

a. Imam Nafi', Imam Abu 'Amru, Imam Ibn Kathir, Imam Ibn ‘Amir, Imam 'Asim melalui riwayat Hafs membaca dengan (يَطُهُرْنَ) yang membawa maksud 'darah mereka berhenti'. Ini menunjukkan bahawa isteri yang haid tidak boleh disetubuhi sehingga berhenti darah haidnya.

b. Imam Hamzah, Imam Kisaei, Imam 'Asim melalui riwayat Abu Bakar dibaca (يَطََُّّرَنَ) yang membawa maksud 'darah mereka berhenti dan sudah mandi jinabah'. Ini menunjukkan isteri yang haid tidak boleh dijima' sehingga terhenti darah haidnya.

\subsubsection{Hukuman terhadap pencuri}

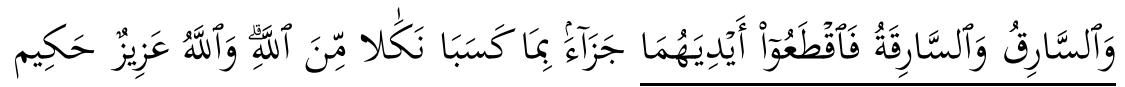

Maksudnya;

"Dan orang lelaki yang mencuri dan orang perempuan yang mencuri maka (hukumnya) potonglah tangan mereka sebagai satu balasan dengan sebab apa yang mereka telah usahakan, (juga sebagai) suatu hukuman pencegah dari Allah, dan (ingatlah) Allah Maha Kuasa, lagi Maha Bijaksana”.

(Surah al-Maidah 5:38)

Ayat ini membicarakan tentang hukum pemotongan tangan bagi pencuri dan persoalan mengenai tangan mana yang perlu didahulukan.

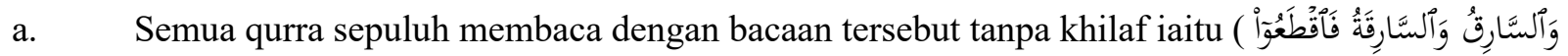

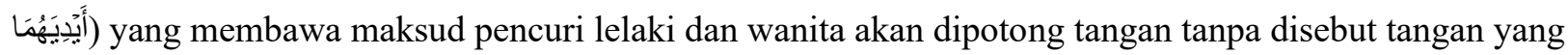
mana.

b. Bacaan syadh dari riwayat Ibn Mas'ud RA dengan bacaan (و السارقون والسارقات فاقطعوا أيمانم) yang membawa maksud pencuri lelaki dan perempuan akan dipotong tangan kanan dahulu.

Menurut Ibn Hazm (t.th), ulama bersepakat bahawa sesiapa yang mencuri akan dipotong tangan kanannya terlebih dahulu dan itulah hudud ke atasnya. Ibn Qudamah juga menaqalkan di dalam kitab al'Mughni bahawa beliau menggunakan bacaan Ibn Masud yang disokong dengan periwayatan daripada Saidina Abu Bakr bahawa dimulai memotong tangan kanan bagi pencuri.

\subsection{KESIMPULAN}

Ilmu qirāāt amat berpengaruh dalam mencorakkan disiplin ilmu yang lain. Ilmu yang bersumberkan wahyu Allah ini sememangnya mendapat tempat dalam kalangan sarjana Islam tidak mengira latar belakang 


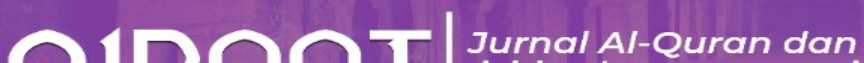 \\ isi-isu kontemporari \\ e-ISSN : 2636-9591}

C3

mereka dalam pengkhususan disiplin ilmu masing-masing. Para fuqaha khususnya sangat memberi penekanan kepada kepelbagaian khilaf qirāāt dalam menentukan kaedah istinbat hukum yang paling tepat. Penentuan hukum tersebut tidak lain untuk memudahkan umat Islam dalam mengikuti syariah Islam seterusnya mendapat keredaan semasa hidup di muka bumi Allah SWT. Ilmu berkaitan qirāāt sangat luas dan masih banyak yang belum diterokai serta memerlukan komitmen para pengkaji untuk melihat sehingga ke peringkat lebih tinggi. Diharapkan penulisan ini mampu memberikan sekurang-kurangnya sedikit penambahan kefahaman berkenaan ilmu Allah SWT.

\section{RUJUKAN}

Al-Quran

'Abd al-Fattah al-Qadi. (2004). al-Budur al-Zahirah. al-Qaherah: Maktabah al-Kuliyyat al-Azhariyyah. Al-Mu'jam al-Arabi al-Asasi. (2003). Munadhamah al-Arabiyah al-Tsaqofah wal ulum: Tunisia

'Adzim, M. F. (2016). Qiraat Al-Qur'an. In M. F. 'Adzim, Makalah Qiraat Al-Qur'an. Fakultas Tarbiyah Dan Ilmu Keguruan (Ftik), Jurusan Pendidikan Agama Islam (Pai), Institut Agama Islam Negeri (Iain), Indonesia.

Badruddin bin Muhammad bin Abdullah al-Zarkashi. (2001). Al-Burhan fi ulum al-Quran. Beirut: Dar alFikir

Ibn al-Jazari, Muhammad bin Muhammad bin Yusuf.(t.th). Munjid al-Muqri'in. al-Qaherah, Dar al-Sha'b. Jalaluddin Abd Rahman al-Suyuti. (t.th). Al-Itqan fi ulum al-Quran. Beirut: Dar Kutub al-Ilmiah

Mohd A'tarahim. (2016). Qiraat Mutawattir dan Kesannya Kepada Hukum Fiqh: Kajian Pengetahuan dan Pendedahan dalam kalangan ilmuan Islam di Terengganu. Tesis Doktor Falsafah, Akademi Pengajian Islam, UM

Mohd Hapiz Mahaiyadin. (2019). Memahami Proses Istinbat Hukum Syarak. Pulau Pinang: Excellent Resources

Majma' al-Lughah al- 'Arabiyyah. (1985). al-Mu'jam al-Wasit. al-Qaherah

Rahmani, D. I. (2010). al-Nazm al-Qurani wa Athruhu fi Ahkam al-Tashri'. Beirut - Lubnan: Dar alBasha'ir al-Islamiyyah

Sabri Mohamad. (2016). Pengaruh Ilmu Qira 'at dalam Pengajian Islam. Jurnal al-Turath; Vol. 1, No. 1; 2016 e-ISSN 0128-0899

Said Ibrahim. (2000). Al-fiqh al-Wadih ala mazhab al-Imam al-Shafi'i. Kuala Lumpur: Darul Ma'rifah Wan Hakimin Wan Mohd Nor, Mohd Asri Ishak, Abdul Hakim Baharudin \& Muhammad Syafee Salihin Hasan. (2017). Pengaruh Qiraat Terhadap Pembentukan Hukum dalam Mazhab al-Syafie. $3^{\text {rd }}$ Muzakarah Fiqh \& International Fiqh Conference ( ${ }^{\text {rd }}$ MFIFC) Shah Alam 15 November 2017 